\title{
Uptake and barriers to the use of geospatial technologies in forest management
}

\author{
Justin Morgenroth $^{1^{*}}$ and Rien Visser $^{2}$
}

\begin{abstract}
Background: A survey was conducted to assess the uptake, and barriers to use, of geospatial tools and technologies amongst New Zealand's plantation forestry sector.

Methods: Responses were received from 17 companies representing 63\% of New Zealand's plantation forest by area. A wide range of company sizes were surveyed (net stocked areas ranged from 4,000 - 200,000 hectares), and 7 of the 17 have international operations.

Results: Survey results suggest that freely available topography, climate, and soil datasets have limited utility, as forest management at the operational level requires higher resolution, remotely sensed data. The most common supplemental data are aerial photography or satellite imagery. High spatial resolution was more highly valued by respondents than spectral diversity (i.e. number of channels); only six companies regularly use imagery containing an infrared band. LiDAR data has been used regularly by only three New Zealand forestry companies, while another six have tried it, suggesting it is an emerging technology in New Zealand. The use of generic GIS software was common amongst all respondents (14 use the ESRI product ArcGIS, three use Maplnfo produced by Pitney Bowes). The utility of ArcGIS, in particular, was enhanced by locally developed extensions designed to address specific operational tasks performed regularly by New Zealand's forestry companies.

Conclusions: While it is clear that geospatial data and tools are generally adopted by New Zealand's forest industry, cost-related barriers prevent their widespread adoption. Interestingly, a lack of staff knowledge was also conceded an impediment to uptake, alluding to the importance of tertiary education in the geospatial sciences and continuing education for practitioners.
\end{abstract}

Keywords: Aerial laser scanning; Aerial photography; GPS; GIS; LiDAR; Remote sensing; Satellite imagery; Survey

\section{Background}

Modern forest management is enhanced by geospatial tools, techniques, and technologies. Advances in Geographic Information Systems (GIS), Global Positioning Systems (GPS), and remote sensing in recent decades have provided new means of undertaking forest productivity assessment (Turcotte 2003), forest inventory (Tomppo et al. 1999; Wulder 1998), harvest planning (Laamanen and Kangas 2011), infrastructure planning (Abdi et al. 2009), log transport (Devlin et al. 2008), carbon reporting (Patenaude et al. 2005), ecosystem classification (Rieman et al. 2000), managing and optimising harvesting systems

\footnotetext{
* Correspondence: justin.morgenroth@canterbury.ac.nz

${ }^{1}$ New Zealand School of Forestry, University of Canterbury, Private Bag 4800, Christchurch 8140, New Zealand

Full list of author information is available at the end of the article
}

(Turcotte 2003), and forest health monitoring (Coops et al. 2006).

Educational advances have developed in parallel with technological advances. As a growing number of forestry graduates are trained in geospatial technologies, forestry companies and government benefit from their skill sets. The number of forestry departments requiring a remote sensing class as part of their degree requirements rose by $5 \%$ (from $75 \%$ to $80 \%$ ) between 1988 (Sader et al. 1989) and 1998 (Sader and Vermillion 2000). The same studies showed that by 1998, 10\% of forestry departments included a GIS class in their curricula, up from $5 \%$ in 1988 . By the year 2000 , nearly $50 \%$ of forestry employers expected that recent graduates had been trained in GIS during their undergraduate education (Sample et al. 1999). A review conducted in 2012 for this

\section{空 Springer}


research showed that of the 50 universities accredited by the Society of American Foresters, 94\% (47 universities) had a dedicated geospatial technology course in their undergraduate curriculum.

With the synergistic improvements of geospatial technologies and education, it is unsurprising that $81 \%$ of recent forestry and natural resource management graduates use GIS at least once a month in their jobs in the United States of America (Merry et al. 2007). A number of software options are available. The ArcGIS software developed by ESRI (Redlands, CA, USA) is used by $57 \%$ of graduates in the field of natural resource management, while 7\% use MapInfo (Pitney Bowes Software Inc., Troy, NY, USA), and 2\% use ERDAS Imagine (Intergraph, Madison, AL, USA). Despite the availability of commercial products, a number of companies develop their own geospatial software, highlighted by $9 \%$ of respondents indicating they used in-house applications (Merry et al. 2007).

This paper expands on previous work by surveying private companies within New Zealand's forestry sector to determine their uptake and use of geospatial technologies. A specific objective of the survey was to determine what remote sensing technologies they use to acquire data for their forest estates and what geospatial software they use to create, edit, and analyse their data. Other objectives of this survey were to determine the common uses of remotely sensed data, the common analysis techniques, and whether barriers existed to acquisition and use of geospatial data for forest management. Although this study focused only on forestry companies in New Zealand, there are international implications. Of the 17 respondents, seven have international forest estates. The tools and technologies used by these respondents may be indicative of those used by those same companies in other countries.

\section{Methods}

A survey was designed to ascertain the level of uptake and identify barriers to use of GPS, GIS, as well as passive (e.g. photography) and active (e.g. LiDAR, RADAR) remote sensing. To ensure that questions were unambiguous and relevant, the survey was administered to three preliminary respondents in separate face-to-face sessions. Based on these preliminary sessions, the survey was revised and then emailed to 18 companies in New Zealand's plantation forestry sector. The survey's intended recipient was each company's geospatial manager (or similar position). A follow-up email was sent to companies if a response had not been received after six weeks.

The selection of companies for participation in the survey was informed by the list of active forest managers in the 2011/2012 New Zealand Plantation Forest Industry Facts \& Figures report (NZ FOA 2012). This process identified 16 medium and large forest management companies in New Zealand. To represent the management of relatively low net stocked areas not listed in the NZ FOA report, two small forest management companies were selected to participate in the survey. The balance of plantation forest not represented in this survey is managed by numerous small organisations and individuals with relatively low net stocked areas.

The survey was split into three segments:

1. Demographic information. Questions pertaining to the respondent and their company including position title, company name, total area managed, and annual harvest volume.

2. Data use and acquisition. Questions pertaining to how companies used existing national datasets for soil (fundamental soil layers from Landcare

Research) and climate (Land Environment of New Zealand (LENZ) database from Landcare Research and/or data from National Institute of Water and Atmosphere (NIWA)), and whether these were supplemented with remotely sensed data including aerial laser scanning data, aerial or satellite imagery, or interferometric synthetic aperture radar (InSAR).

3. Data analysis. Questions pertaining to the software used for analysis and interpretation of geospatial data, including typical uses or outputs.

The survey used a mix of open-ended and closed questions. Open-ended questions followed the structured closed questions to allow respondents to provide additional information and explain their choice of answer in the closed questions. In the results sections that follow, Figures 1 and 2 as well as Tables 1 and 2 provide a summary of the closed questions, while answers to the open-ended questions are used to explain patterns in the results of closed questions.

\section{Results}

\section{Respondent profiles}

In all, 17 of the 18 companies contacted responded to the survey ( $94 \%$ response rate). The total area of forest managed by the respondents was approximately $1,158,000$ hectares (ha) or $63 \%$ of the 1.72 million ha in New Zealand's plantation forest estate (NZ FOA 2012). Individual companies represented in the survey managed total forest areas ranging from 4,000 ha to 200,000 ha. Small companies did not always employ a geospatial manager or similar position, so the most appropriate staff member responded as necessary (Table 3 ).

\section{Data use and acquisition by forestry companies}

Data acquisition for the management of forested land is supported by the availability of national datasets. Digital topographic maps (1:50,000 and 1:250,000) and spatially 


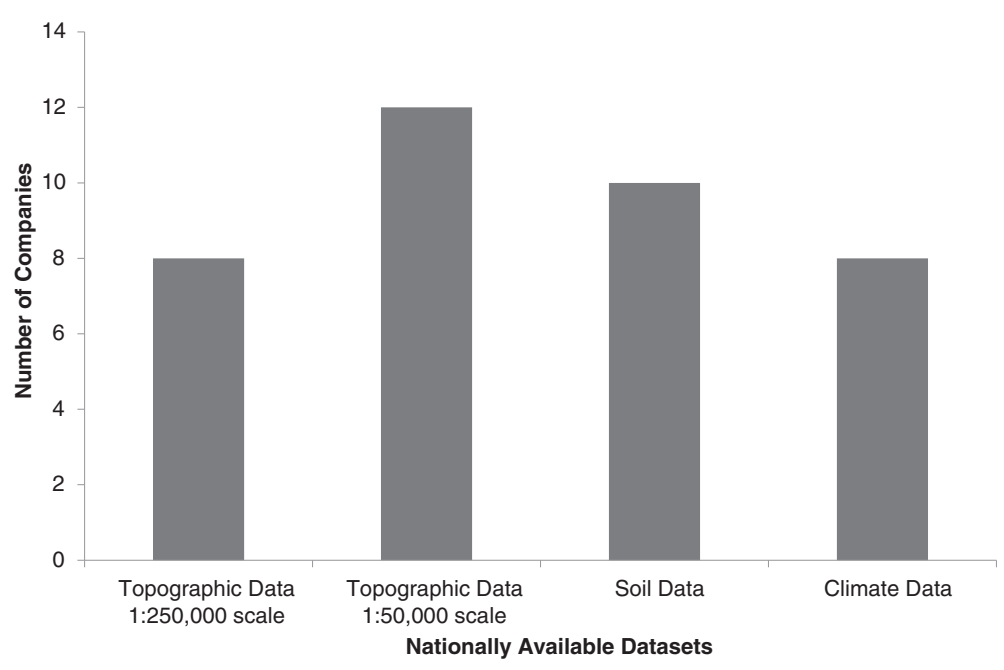

Figure 1 Frequency of use of nationally available topographic, soil, and climate data by forestry companies.

explicit soil and climate data are freely available in a number of common data formats (.kml, .tif, .shp). Forestry companies made use of topographic data with 12 of the 17 (71\%) using the 1:50,000 scale and eight (47\%) using the 1:250,000 scale topographic maps (Figure 1). Just over half of all respondents ( 9 of 17, 53\%) answered that the scale of both these datasets was too coarse, so they created finer scale topographic maps in-house. National soil datasets (e.g. texture, available water, chemistry) were used by 10 (59\%) companies, while eight (47\%) used climate data (e.g. precipitation, temperature) (Figure 1).

Additional information about land and trees within forest estates was obtained by companies using remote sensing technologies. Survey results of the acquisition of remotely sensed data and the barriers to their use are presented in Table 1. Aerial photography was the most widely acquired form of remotely sensed data. Very high resolution, aerial photography (captured from aeroplanes) was regularly used by 15 of the 17 (88\%) companies surveyed; the two exceptions cited cost as the reason for not using it. Satellite-derived, high resolution, imagery was used by 3 of 16 (17\%) companies regularly, while 10 (59\%) other companies had tried to work with the data. This technology was not perceived to provide any benefits by three companies, while seven (41\%) companies suggested cost was a deterrent, and one (6\%) company cited that their staff lacked the knowledge necessary for its use. The uses of aerial photographs were varied but included tree-crop mapping prior to silviculture, at midrotation, prior to harvest, and following harvest. Other uses included identifying roads, skids, or canopy gaps formed by wind or other environmental events. Finally,

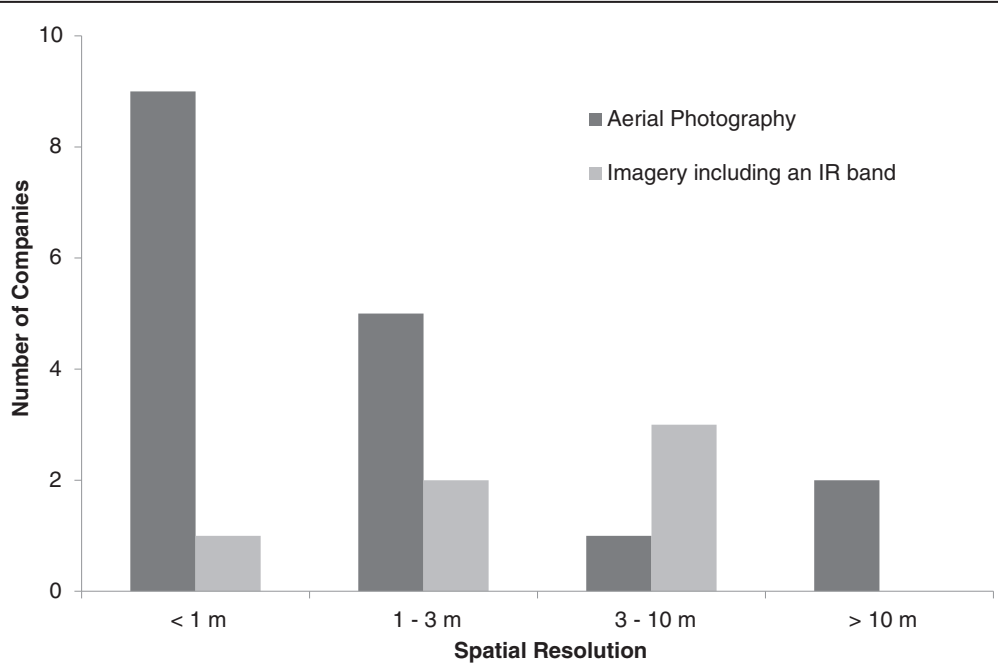

Figure 2 Improved spectral diversity (i.e. the inclusion of an IR band) reduces spatial resolution. 
Table 1 Uptake and barriers to use of remote sensing (RS) data for forestry companies

\begin{tabular}{|c|c|c|c|c|c|c|}
\hline \multirow[t]{2}{*}{ Technology type } & \multicolumn{3}{|c|}{ Use of RS technology } & \multicolumn{3}{|c|}{ Reason for not regularly using RS technology } \\
\hline & Tried & Use regularly & Not considered & No perceived benefits & Cost & Lack of staff knowledge \\
\hline Very high resolution aerial $R G B$ & 2 & 15 & 0 & 0 & 2 & 0 \\
\hline High resolution aerial $R G B$ & 10 & 3 & 0 & 3 & 7 & 1 \\
\hline Aerial $R G B+\mathbb{R}$ & 3 & 6 & 3 & 3 & 5 & 1 \\
\hline Aerial LiDAR & 6 & 3 & 0 & 1 & 11 & 4 \\
\hline Terrestrial LiDAR & 0 & 0 & 3 & 9 & 11 & 5 \\
\hline Radar & 0 & 0 & 12 & 4 & 3 & 4 \\
\hline
\end{tabular}

aerial photographs were used as base layers for maps and in presentations.

Satellite imagery including an infrared (IR) wavelength had been trialled by three (18\%) companies and was regularly used by six (35\%) companies (Table 1 ). While three (18\%) companies had never considered acquiring an IR wavelength, three (18\%) didn't believe there were benefits, five (29\%) suggested the cost was unjustifiable, and one (6\%) said they lacked the staff knowledge to work with the data. Survey responses showed that acquisition of an IR wavelength provided companies with the same benefits as three visible band (Red Green Blue, RGB) photography or imagery, but also the ability to map and quantify mixed species stands, to detect vegetation change and growth differences over time, to identify invasive species (Pinus contorta Doug.), to detect disease, and to identify areas where erosion had occurred. While more applications were possible with the inclusion of an IR wavelength, spatial resolution generally declined (Figure 2). This is not to say that the inclusion of an IR band necessarily degrades spatial resolution, but rather that acquisition of very high resolution aerial photography was typically done with a RGB sensor, while the IR band was often only collected in satellite imagery with lower resolution.

Eight (47\%) companies acquired aerial photography or satellite imagery with a sub-metre resolution and another five (29\%) worked with finer than $3 \mathrm{~m}$ resolution. One (6\%) company acquired imagery with resolution between $3-10 \mathrm{~m}$, and two (12\%) companies acquired $10+m$ resolution imagery. In contrast, only one $(6 \%)$ company acquired sub-metre resolution for aerial photographs or satellite imagery including an IR band, while two (12\%) acquired better than $3 \mathrm{~m}$ resolution and three (18\%) others acquired better than $10 \mathrm{~m}$ resolution. Companies were also asked whether improved spatial resolution was desirable. There was consensus amongst respondents that finer resolution was desirable, with one $(6 \%)$ company suggesting that their recent acquisition of $25 \mathrm{~cm}$ resolution imagery allowed mapping of site preparation and young trees which was previously not possible with $50 \mathrm{~cm}$ resolution imagery. Two (12\%) companies suggested that while resolution improvements were important, cloud and shadow-free imagery were more important.

Table 2 Uptake and barriers to use of geospatial software amongst forestry companies

\begin{tabular}{|c|c|c|c|c|c|c|}
\hline \multirow{2}{*}{ Software class } & \multirow{2}{*}{ Software product } & \multirow{2}{*}{$\begin{array}{l}\text { No. companies using } \\
\text { software }\end{array}$} & \multicolumn{4}{|c|}{ Reason for not using software } \\
\hline & & & $\begin{array}{c}\text { Use an alternative } \\
\text { product }\end{array}$ & $\begin{array}{c}\text { No perceived } \\
\text { benefit }\end{array}$ & Cost & $\begin{array}{l}\text { Lack of staff } \\
\text { Knowledge }\end{array}$ \\
\hline \multirow{4}{*}{$\begin{array}{l}\text { Geographic information } \\
\text { system }\end{array}$} & ArcGIS & 14 & 3 & 0 & 1 & 1 \\
\hline & Maplnfo & 3 & 11 & 4 & 1 & 1 \\
\hline & $\begin{array}{l}\text { Open-source or freely } \\
\text { accessible GIS }\end{array}$ & 1 & 11 & 5 & 4 & 2 \\
\hline & Google Earth & 9 & 0 & 3 & 0 & 0 \\
\hline \multirow{3}{*}{ Image analysis } & ERDAS imagine & 2 & 3 & 2 & 5 & 6 \\
\hline & ENVI & 0 & 4 & 3 & 7 & 7 \\
\hline & e-Cognition & 0 & 2 & 4 & 6 & 8 \\
\hline \multirow{3}{*}{$\begin{array}{l}\text { Specialist forestry } \\
\text { software }\end{array}$} & ATLAS GeoMaster & 6 & 5 & 2 & 4 & 1 \\
\hline & CYANZ & 8 & 4 & 1 & 0 & 1 \\
\hline & LoggerPC & 3 & 4 & 5 & 0 & 2 \\
\hline
\end{tabular}


Table 3 A description of the respondents' positions within companies and the total area managed by each company

\begin{tabular}{crr}
\hline Company ID & Area managed (ha) & Position of respondent \\
\hline $\mathbf{1}$ & 4,000 & Senior GIS Analyst \\
$\mathbf{2}$ & 4,000 & Resource Manager \\
$\mathbf{3}$ & 15,000 & Forest Supervisor \\
$\mathbf{4}$ & 16,000 & Forest Analyst \\
$\mathbf{5}$ & 20,000 & Forest and GIS Manager \\
$\mathbf{6}$ & 21,000 & Technical Forestry Manager \\
$\mathbf{7}$ & 23,000 & Technical and Resource Manager \\
$\mathbf{8}$ & 30,000 & GIS Officer \\
$\mathbf{9}$ & 34,000 & Environmental and \\
& & Technical Manager \\
$\mathbf{1 0}$ & 35,000 & Information Systems Manager \\
$\mathbf{1 1}$ & 60,000 & Forest Information Analyst \\
$\mathbf{1 2}$ & 78,000 & Business Development Analyst \\
$\mathbf{1 3}$ & 129,000 & Forest Information Manager \\
$\mathbf{1 4}$ & 140,000 & Environment Manager \\
$\mathbf{1 5}$ & 150,000 & GIS Manager \\
$\mathbf{1 6}$ & 200,000 & Land Information Manager \\
$\mathbf{1 7}$ & 200,000 & Forest Information Team Leader \\
\hline
\end{tabular}

Data capture using aerial laser scanning (ALS), also known as LiDAR, has not been implemented by as many companies as has photogrammetric remote sensing technologies. Only 3 of 17 (18\%) companies regularly use ALS data, but six (35\%) others have tried it (Table 1). At present, cost appears prohibitive for most companies with 11 (65\%) suggesting that price was their reason for not regularly acquiring ALS data. Four (24\%) companies lacked the staff expertise to use ALS data, while only a single (6\%) company did not believe there were benefits to be gained. Four main products were derived from ALS data; eight (47\%) companies produced digital terrain models (DTM), seven (41\%) produced canopy height models (CHM), four (24\%) produced volume or biomass estimates, and two (12\%) produced stem counts. Respondents suggested that these outputs, in conjunction with ALS intensity data assisted with engineering efficiency, forest inventory, harvest planning, stream network mapping, flood protection modelling, and disease assessment. As ALS is an emerging technology that can produce useful data, a number of companies expressed a desire to increase their use of the data. The list of future objectives included improved stem counting algorithms, automated stand delineation, identification of undergrowth structure, creation of biodiversity indices, and resource assessment (e.g. pre-harvest inventory, silvicultural scheduling, and mid-rotation yield tables).
Terrestrial LiDAR (TLS - terrestrial laser scanning) and InSAR technologies have not been adopted by New Zealand's forestry sector. None of the 17 companies surveyed had tried either technology. With respect to TLS, nine (53\%) respondents did not believe there was any benefit, five (29\%) companies lacked the staff expertise, and three (18\%) had never considered using the technology. Of those that had considered using TLS, 11 (65\%) companies perceived cost as being a barrier. Interferometric synthetic aperture radar technology was generally not even considered for forest management (12 (71\%) companies). Four (24\%) companies suggested that staff knowledge was insufficient, while three (18\%) companies believed cost was too high and four (24\%) companies did not perceive any benefit to the technology.

\section{Analysis of geospatial data by forestry companies}

The ArcGIS suite of programs is the primary geographic information system used by New Zealand's forestry companies (Table 2). Of the 17 companies surveyed, 14 (82\%) used ArcGIS and three (18\%) used MapInfo. Some companies used the free software products Quantum GIS (one (6\%) company) and Google Earth (Google Inc., Mountainview, CA, USA) (nine (53\%) companies) to supplement ArcGIS and MapInfo. The three (18\%) companies using MapInfo in place of ArcGIS cited cost and lack of staff knowledge as the reasons for their software choice (Table 2).

Image analysis software was not used frequently, with only two (12\%) companies using ERDAS Imagine and none using ENVI (Exelis Inc., Boulder, CO, USA) or eCognition (Trimble GeoSpatial, Munich, Germany). Cost and lack of staff knowledge appear to be the greatest barriers to use, though some companies perceive no benefit and others use alternative products.

Specialist software designed specifically for forestry applications has been developed and adopted by a number of companies in New Zealand's forestry sector. Six (35\%) companies use ATLAS GeoMaster (ATLAS Technology, Rotorua, NZ), seven (41\%) use CYANZ (CYANZ Forestry Solutions Ltd., Rotorua, NZ) and three (18\%) use Logger PC (United States Department of Agriculture Forestry Service, San Dimas, CA, USA). It should be noted that companies were given the opportunity to name any other geospatial software they used; one $(6 \%)$ company used CENGEA resource planning and management software (CENGEA Solutions Inc., Vancouver, Canada).

Companies were asked about the tasks they performed with the software (listed in Table 2). The ArcGIS software was used as a forest record system (sometimes in conjunction with ATLAS GeoMaster) and as an operational support tool for planting, silviculture assessment, quality control, forest inventory, harvest planning, engineering, and environmental analysis. Specific uses of 
ArcGIS software included: processing and producing outputs (e.g. DTM, CHM) from ALS data pointclouds, network analysis for cartage, creating and editing vector boundaries for features of interest (e.g. forest patches, roads, landings, property boundaries, canopy gaps), risk analysis and climate modelling using the Spatial Analyst extension, aerial image analysis, random and grid-based plot centre generation, working with GPS data, area and distance measurements, map production. The use of ATLAS GeoMaster provided companies with a spatial and temporal forest record system. The software is designed specifically for forest management and allowed companies to manage their stand record history and operations planning. Google Earth provided companies with a simple way of viewing the landscape or features of interest. It was especially used when in-house aerial photography was not up to date. The CYANZ software was identified as a harvest planning tool, however, three (18\%) companies suggested that they had recently, or were in the process of, switching over to CHPS (Geographic Business Solutions Ltd., Auckland, NZ), an extension of ArcGIS.

\section{Discussion}

\section{Data use and acquisition}

The survey results showed a greater number of companies used the large scale 1:50,000 (fine) than the small scale 1:250,000 (coarse) topographic maps. Also, 53\% of respondents stated that they produce operational scale topographic maps in-house, as even the relatively large scale 1:50,000 maps were too coarse. The inference that topographic data resolution is poor for operational use is further supported by the fact that DTMs were the most produced ALS data output by forestry companies. Evidently, the benefits of a fine-resolution topographic model can outweigh the cost associated with ALS.

Questions about the utility of soil and climate datasets must also be asked considering the low rate of use of these freely available datasets amongst forestry companies. These datasets are based on a limited number of point observations and are derived using interpolation algorithms such that error at the forest stand or block scale is probable (Leathwick et al. 2002). Moreover, the distribution of observation points is much denser in agriculturally productive regions (Leathwick et al. 2002), whereas plantation forestry is generally confined to marginally productive lands. Another potential explanation is that productivity models used by forest management companies already incorporate climate and/or soil data (e.g. Palmer et al. 2010), such that use of additional soil or climate data would be redundant. So, despite their fine resolution $(25 \mathrm{~m})$, the inherent constraints of soil and climate datasets limits their use in operational forestry.
The data used most by forestry companies were aerial photographs, with the vast majority requiring finer than 3 $\mathrm{m}$ spatial resolution imagery. Finer resolution imagery was desirable as increased accuracy allowed for broader application. Historic trends suggest that finer resolution is all but assured; as complementary metal-oxide-semiconductor (CMOS) sensor technology continues to improve exponentially (Fossum 1997), resolution improvements will follow. Imagery providers will undoubtedly be motivated to adopt new sensor technology in order to provide customers with the best possible aerial photographs.

Only one third of forestry companies acquired aerial photographs or satellite imagery including an infrared wavelength despite clear benefits for assessing forest health (e.g. Coops et al. 2006; Olthof and King 2000), monitoring structure (e.g. Hill et al. 2011), and for planning (Watt and Watt 2011). Given that six (35\%) respondents had either not considered or saw no benefit to an IR band, it is possible that the advantages of this imagery are not well understood. This is supported by comments from respondents who did not acquire multi-spectral imagery but desired shadow-free aerial photography or satellite imagery. Because IR wavelengths falls outside the visible light spectrum, indices (e.g. normalised difference vegetation index) derived from multi-spectral imagery can provide information about the forest resource that is obscured by shade in RGB imagery (Greer et al. 1990), thus solving the desire for shadow-free imagery. Perhaps it will be adopted in favour of RGB photography or imagery as forestry companies learn more about the benefits of multi-spectral imagery. Multi-spectral imagery appears especially useful for monitoring forest structure when combined with ALS data (Donoghue and Watt 2006).

Few forestry companies in New Zealand regularly make use of ALS data, but the fact that twice as many companies have tried the data compared to those who use it regularly might suggest that uptake is progressing, albeit slowly. Supporting that inference is the fact that all forestry companies had at least considered using ALS data and only one (6\%) company didn't believe there were any benefits. As suggested by the responses, the major barrier to uptake is the cost, which depends on the size and degree of fragmentation of the forest estate (Adams et al. 2011). Typically, the cost per hectare decreases with increasing forest size and connectivity. Anecdotally, the value for cost question is often discussed by forest information analysts and managers. Though the primary output of ALS data in New Zealand remains the digital terrain model, the derivation of canopy height models (González-Ferreiro et al. 2012), site index models (Chen and Zhu 2012), carbon estimates (Beets et al. 2012), stocking (Stone et al. 2011), and fuel loading estimates (Wing et al. 2012) might add value and justify the 
cost. As with the cost of aerial photography and satellite imagery, which is decreasing for a given resolution, it is reasonable to expect that the cost of acquiring ALS data will decrease, potentially removing cost as a significant barrier to uptake in the future.

The lack of staff knowledge with respect to ALS data analysis cannot be overlooked, but should not be considered an insurmountable barrier. With continued integration of GIS and remote sensing education in forestry degrees (see Sader and Vermillion 2000), graduates will have the skills and confidence to work with these complex datasets. The significant benefits for a variety of forestry activities derived from ALS (Akay et al. 2009) are sufficient to garner interest by New Zealand's forestry companies despite the barriers to uptake.

The same cannot be said for either terrestrial LiDAR or radar remote sensing technologies. Neither technology has been trialled by any of the forestry companies surveyed. With respect to TLS, the perceived lack of benefit is possibly justified given the inherent issue of scale. But, while TLS is not designed to provide details of the whole forest, there are some unrecognised benefits to using TLS at the plot level. Terrestrial laser scanning data can be used to produce spatially accurate 3D models of trees for accurately determining $\log$ yields and stand values (Murphy 2008), species differentiation (Puttonen et al. 2010), and even canopy gap fraction and leaf area index assessment (Jupp et al. 2009). A comprehensive review of applications of terrestrial laser scanning in forestry can be found in Dassot et al. (2011). Some of these benefits are certainly applicable to New Zealand's forestry sector so potential exists for the technology to be adopted by some companies once barriers to use are overcome.

The major benefit to the use of radar imagery is its ability to acquire imagery irrespective of weather or illumination (Balzter 2001). It has proven especially useful for land cover mapping of vast regions, like the world's rainforests (Rosenqvist et al. 2000). But with no companies responding that they use InSAR imagery, it is evident that the technology is simply not considered in modern forest management in New Zealand. It is assumed that: (a) the spatial resolution of InSAR, with units of tens of metres (Balzter 2001), cannot provide sufficient detail for operational use; and (b) the relationship between radar backscatter and biomass becomes saturated at higher biomass levels (Dobson et al. 1992; Imhoff 1995), again limiting utility of InSAR for operational use. Common tasks like boundary mapping and feature identification are more accurate when using imagery from passive optical sensors, where resolution is generally expressed in centimetres. Though InSAR can be used for volume and biomass estimation, accuracy of synthetic aperture radar (SAR) decreases sharply above volumes of only $150 \mathrm{~m}^{3} \mathrm{ha}^{-1}$ (Koch 2010). This is untenable in NZ's plantation forestry sector, where wood volume exceeds this threshold by half way through a rotation (Ministry for Primary Industries 2011).

\section{Analysis of geospatial data}

The ArcGIS software suite was favoured by New Zealand's forestry companies for analysing, storing, and presenting their forestry-related geographic data. Preference for ArcGIS over MapInfo has previously been reported, as has low uptake and use of image analysis software (Merry et al. 2007). This previous research had surveyed natural resource managers, so the context was not identical to this study, but nevertheless the agreement between studies is indicative of preference for, and utility of, specific software. It is possible that even fewer forestry companies will invest in specialised image-analysis software given improvements in image analysis in recent versions of ArcGIS.

Another similarity between the Merry et al. (2007) study and the current one is the use of specialist software. Though generic GIS software packages are used by all New Zealand forestry companies who responded to this survey, there is a clear need for software designed to achieve specific tasks. As an example, ATLAS GeoMaster allows spatial and temporal monitoring of operational aspects of forest management and is used by approximately one third of respondents. It integrates with ArcGIS, thus allowing users to benefit from the latter's familiar user interface and analytical power, but also the specialised forest management functions within ATLAS Geomaster. The development of extensions for ArcGIS is a direction also taken by Geographic Business Solutions Ltd., and their CHPS software, which is specifically designed to aid with cable harvest planning. Intimate knowledge of the needs of New Zealand forest industry has allowed these local companies to develop these niche software products.

\section{Conclusion}

New Zealand relies on the forestry sector to satisfy both a domestic demand for wood as well as a large export market. While New Zealand's various government departments and crown research institutes can support industry by supplying topographic, climate, and soil data (Land Information New Zealand 2009), the resolution of currently available data is generally too coarse to be useful at an operational level. This gap in data availability has forced companies in New Zealand's plantation forestry sector to supplement these freely available datasets with site-specific ground-based data and remotely sensed data. These results suggest that government could support forest industry by developing a national 
spatial data infrastructure comprising freely-available high-resolution data. As such, it is well timed that Land Information New Zealand (LINZ) are leading a coordinated governmental effort to develop a national infrastructure for spatial data, including topographic data. This represents an opportunity for the forestry sector to communicate its needs and ensure that national topographic maps are available at a scale useful for operational forestry.

Acquisition of finer than $3 \mathrm{~m}$ resolution RGB imagery is common, but few companies have explored the additional benefits that can be gained by acquiring imagery including an infrared band. If the plantation forestry sector diversifies the species planted, there may be greater uptake of multi-spectral imagery. The global trend towards using LiDAR data in forest management has been adopted by a small number of New Zealand forestry companies, but interest is widespread. Tertiary education providers need to ensure that they are providing graduates with the necessary skills to understand and analyse LiDAR data, so that as cost becomes less of a barrier to uptake, lack of staff knowledge does not become the limiting factor.

The use of generic GIS software (ArcGIS or MapInfo) was common amongst all respondents, but it is also evident that software designed to address specific operational tasks are highly useful for New Zealand's forestry companies. While the forestry sector's core export will continue to be wood, the area of software development for forestry presents an opportunity to export a highvalue technology. New Zealand software products such as ATLAS GeoMaster and CHPS are well placed to gain global interest as they integrate with ArcGIS, which has an estimated $40 \%$ of the global GIS market share.

These results represent the responses of 17 forestry companies controlling $63 \%$ of New Zealand's plantation forestry estate. Of the companies represented, seven also have international forestry operations, so these results may yield insight into global adoption of geospatial tools and technologies.

\section{Abbreviations}

ALS: Aerial laser scanning; CHM: Canopy height model;

CMOS: Complementary metal-oxide-semiconductor; DTM: Digital terrain model; GIS: Geographic information system; GPS: Geographic positioning system; InSAR: Interferometric synthetic aperture radar; IR: infra-red; LiDAR: Light detection and ranging; NZ: New Zealand; RGB: Red green blue; SAR: Synthetic aperture radar; TLS: Terrestrial laser scanning; USA: United States of America.

\section{Competing interests}

The authors declare that they have no competing interests.

\section{Authors' contributions}

JM identified concept for paper. JM and RV created survey design, analysed data, and wrote paper together. Both authors read and approved the final manuscript.

\section{Author's information}

Dr. Justin Morgenroth is a Lecturer in geospatial technologies at the New Zealand School of Forestry at the University of Canterbury. Dr. Rien Visser is an Associate Professor and Director of Studies for Forest Engineering at the New Zealand School of Forestry at the University of Canterbury.

\section{Acknowledgements}

Thanks to Christian Pilaar, Tim Farrier, and Aaron Gunn for help in refining the survey questions. Thanks also to Riki Green for help with analysis of the results.

\section{Author details}

${ }^{1}$ New Zealand School of Forestry, University of Canterbury, Private Bag 4800, Christchurch 8140, New Zealand. ${ }^{2}$ New Zealand School of Forestry, University of Canterbury, Private Bag 4800, Christchurch 8140, New Zealand.

Received: 12 June 2013 Accepted: 25 November 2013

Published: 11 Dec 2013

\section{References}

Abdi, E, Majnounian, B, Darvishsefat, A, Mashayekhi, Z, \& Sessions, J. (2009). A GIS-MCE based model for forest road planning. Journal of Forest Science, 55(4), 171-176.

Adams, T, Brack, C, Farrier, T, Pont, D, \& Brownlie, R. (2011). So you want to use LiDAR? - a guide on how to use LiDAR in forestry. New Zealand Journal of Forestry, 55(4), 19-23.

Akay, AE, Oǧuz, H, Karas, IR, \& Aruga, K. (2009). Using LiDAR technology in forestry activities. Environmental Monitoring and Assessment, 151(1-4), 117-125.

Balzter, H. (2001). Forest mapping and monitoring with interferometric synthetic aperture radar (InSAR). Progress in Physical Geography, 25(2), 159-177.

Beets, PN, Brandon, AM, Goulding, CJ, Kimberley, MO, Paul, TSH, \& Searles, N. (2012). The national inventory of carbon stock in New Zealand's pre-1990 planted forest using a LiDAR incomplete-transect approach. Forest Ecology and Management, 280, 187-197.

Chen, Y, \& Zhu, X. (2012). Site quality assessment of a Pinus radiata plantation in Victoria, Australia, using LiDAR technology. Southern Forests, 74(4), 217-227.

Coops, NC, Johnson, M, Wulder, MA, \& White, JC. (2006). Assessment of QuickBird high spatial resolution imagery to detect red attack damage due to mountain pine beetle infestation. Remote Sensing of Environment, 103(1), 67-80.

Dassot, M, Constant, T, \& Fournier, M. (2011). The use of terrestrial LiDAR technology in forest science: application fields, benefits and challenges. Annals of Forest Science, 68(5), 959-974.

Devlin, GJ, McDonnell, K, \& Ward, S. (2008). Timber haulage routing in Ireland: an analysis using GIS and GPS. Journal of Transport Geography, 16(1), 63-72.

Dobson, MC, Ulaby, FT, LeToan, T, Beaudoin, A, Kasischke, ES, \& Christensen, N. (1992). Dependence of radar backscatter on coniferous forest biomass. IEEE Transactions on Geoscience and Remote Sensing, 30(2), 412-415.

Donoghue, DNM, \& Watt, PJ. (2006). Using LiDAR to compare forest height estimates from IKONOS and Landsat ETM + data in Sitka spruce plantation forests. International Journal of Remote Sensing, 27(11), 2161-2175.

Fossum, ER. (1997). CMOS image sensors: electronic camera-on-a-chip. IEEE Transactions on Electron Devices, 44(10), 1689-1698. doi:10.1109/16.628824.

González-Ferreiro, E, Diéguez-Aranda, U, \& Miranda, D. (2012). Estimation of stand variables in Pinus radiata D. Don plantations using different LiDAR pulse densities. Forestry, 85(2), 281-292.

Greer, JD, Hoppus, ML, \& Lachowski, HM. (1990). Color infrared photography for resource management: unique attributes improve vegetation mapping and assessment. Journal of Forestry, 88(7), 12-17.

Hill, RA, Boyd, DS, \& Hopkinson, C. (2011). Relationship between canopy height and Landsat ETM + response in lowland Amazonian rainforest. Remote Sensing Letters, 2(3), 203-212.

Imhoff, ML. (1995). Radar backscatter and biomass saturation: ramifications for global biomass inventory. IEEE Transactions on Geoscience and Remote Sensing, 33(2), 511-518.

Jupp, DLB, Culvenor, DS, Lovell, JL, Newnham, GJ, Strahler, AH, \& Woodcock, CE. (2009). Estimating forest LAl profiles and structural parameters using a ground-based laser called 'Echidna' ${ }^{\oplus}$. Tree Physiology, 29(2), 171-181.

Koch, B. (2010). Status and future of laser scanning, synthetic aperture radar and hyperspectral remote sensing data for forest biomass assessment. ISPRS Journal of Photogrammetry and Remote Sensing, 65(6), 581-590.

Laamanen, R, \& Kangas, A. (2011). Large-scale forest owner's information needs in operational planning of timber harvesting - some practical views in Metsähallitus, Finnish state-owned enterprise. Silva Fennica, 45(4), 711-727.

Land Information New Zealand. (2009). Spatial information in the New Zealand economy. NZ: Wellington. 
Leathwick, J, Morgan, F, Wilson, G, Rutledge, D, McLeod, M, \& Johnston, K. (2002). Land environments of New zealand: a technical guide. NZ: Wellington.

Merry, KL, Bettinger, P, Clutter, M, Hepinstall, J, \& Nibbelink, NP. (2007). An assessment of geographic information system skills used by field-level natural resource managers. Journal of Forestry, 105(7), 364-370.

Ministry for Primary Industries. (2011). National exotic forest regional yield tables. Wellington, NZ.

Murphy, G. (2008). Determining stand value and log product yields using terrestrial lidar and optimal bucking: a case study. Journal of Forestry, 106(6), 317-324.

NZ FOA. (2012). New Zealand plantation forest industry facts and figures. Wellington, NZ: New Zealand Forest Owners Association Inc.

Olthof, I, \& King, DJ. (2000). Development of a forest health index using multispectral airborne digital camera imagery. Canadian Journal of Remote Sensing, 26(3), 166-176.

Palmer, DJ, Watt, MS, Kimberley, MO, Hock, BK, Payn, TW, \& Lowe, DJ. (2010). Mapping and explaining the productivity of Pinus radiata in New Zealand. New Zealand Journal of Forestry, 55(1), 15-21.

Patenaude, G, Milne, R, \& Dawson, TP. (2005). Synthesis of remote sensing approaches for forest carbon estimation: reporting to the Kyoto Protocol. Environmental Science and Policy, 8(2), 161-178.

Puttonen, E, Suomalainen, J, Hakala, T, Räikkönen, E, Kaartinen, H, Kaasalainen, S, \& Litkey, P. (2010). Tree species classification from fused active hyperspectral reflectance and LIDAR measurements. Forest Ecology and Management, 260 (10), 1843-1852.

Rieman, BE, Lee, DC, Thurow, RF, Hessburg, PF, \& Sedell, JR. (2000). Toward an integrated classification of ecosystems: defining opportunities for managing fish and forest health. Environmental Management, 25(4), 425-444.

Rosenqvist, Å, Shimada, M, Chapman, B, Freeman, A, De Grandi, G, Saatchi, S, \& Rauste, Y. (2000). The global rain forest mapping project-a review. International Journal of Remote Sensing, 21(6-7), 1375-1387.

Sader, SA, \& Vermillion, S. (2000). Remote sensing education: an updated survey. Journal of Forestry, 98(4), 31-37.

Sader, SA, Hoffer, RM, \& Johnson, EW. (1989). The status of remote-sensing education: a 1988 survey of US and Canadian forestry schools. Journal of Forestry, 87(10), 25-30.

Sample, VA, Ringgold, PC, Block, NE, \& Giltmier, JW. (1999). Forestry education: adapting to the changing demands. Journal of Forestry, 97(9), 4-10.

Stone, C, Penman, T, \& Turner, R. (2011). Determining an optimal model for processing lidar data at the plot level: results for a Pinus radiata plantation in New South Wales, Australia. New Zealand Journal of Forestry Science, 41, 191-205.

Tomppo, E, Goulding, C, \& Katila, M. (1999). Adapting finnish multi-source forest inventory techniques to the New Zealand preharvest inventory. Scandinavian Journal of Forest Research, 14(2), 182-192. doi:10.1080/02827589950152917.

Turcotte, P. (2003). Multidata and opti-grade: two innovative solutions to better manage forestry operations. Paper presented at the The Proceedings of the 2nd International Precision Forestry Symposium: Seattle, WA.

Watt, P, \& Watt, M. (2011). Applying satellite imagery for forest planning New Zealand Journal of Forestry, 56(1), 23-25.

Wing, BM, Ritchie, MW, Boston, K, Cohen, WB, Gitelman, A, \& Olsen, MJ. (2012). Prediction of understory vegetation cover with airborne lidar in an interior ponderosa pine forest. Remote Sensing of Environment, 124, 730-741.

Wulder, M. (1998). Optical remote-sensing techniques for the assessment of forest inventory and biophysical parameters. Progress in Physical Geography, $22(4), 449-476$

\subsection{6/1179-5395-43-16}

Cite this article as: Morgenroth and Visser: Uptake and barriers to the use of geospatial technologies in forest management. New Zealand Journal of Forestry Science 2013, 43:16 